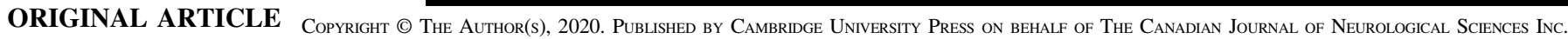

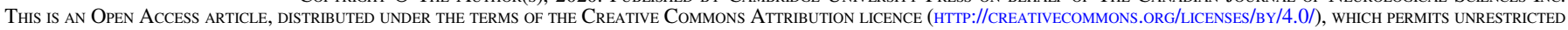
RE-USE, DISTRIBUTION, AND REPRODUCTION IN ANY MEDIUM, PROVIDED THE ORIGINAL WORK IS PROPERLY CITED.

\title{
Disparities in Deep Brain Stimulation Use for Parkinson's Disease in Ontario, Canada
}

\author{
James A.G. Crispo (), Melody Lam, Britney Le, Lucie Richard, \\ Salimah Z. Shariff, Dominique R. Ansell, Melanie Squarzolo, \\ Connie Marras, Allison W. Willis, Dallas Seitz
}

\begin{abstract}
Objective: To examine whether sociodemographic characteristics and health care utilization are associated with receiving deep brain stimulation (DBS) surgery for Parkinson's disease (PD) in Ontario, Canada. Methods: Using health administrative data, we identified a cohort of individuals aged 40 years or older diagnosed with incident PD between 1995 and 2009. A case-control study was used to examine whether select factors were associated with DBS for PD. Patients were classified as cases if they underwent DBS surgery at any point 1-year after cohort entry until December 31,2016. Conditional logistic regression modeling was used to estimate the adjusted odds of DBS surgery for sociodemographic and health care utilization indicators. Results: A total of 46,237 individuals with PD were identified, with $543(1.2 \%)$ receiving DBS surgery. Individuals residing in northern Ontario were more likely than southern patients to receive DBS surgery [adjusted odds ratio $(\mathrm{AOR})=2.23,95 \%$ confidence interval $(\mathrm{CI})=1.15-4.34$ ]; however, regional variations were not observed after accounting for medication use among older adults $(\mathrm{AOR}=1.04,95 \% \mathrm{CI}=0.26-4.21)$. Patients living in neighborhoods with the highest concentration of visible minorities were less likely to receive DBS surgery compared to patients living in predominantly white neighborhoods ( $\mathrm{AOR}=0.27,95 \% \mathrm{CI}=0.16-0.46$ ). Regular neurologist care and use of multiple PD medications were positively associated with DBS surgery. Conclusions: Variations in use of DBS may reflect differences in access to care, specialist referral pathways, health-seeking behavior, or need for DBS. Future studies are needed to understand drivers of potential disparities in DBS use.
\end{abstract}

RÉSUMÉ : Variations dans l'utilisation de la stimulation cérébrale profonde en lien avec la maladie de Parkinson (Ontario, Canada). Objectif: Analyser dans quelle mesure certaines caractéristiques sociodémographiques et l'utilisation des soins de santé peuvent être associées en Ontario (Canada) à la chirurgie de stimulation cérébrale profonde (SCP) si l'on est atteint de la maladie de Parkinson (MP). Méthodes: Au moyen de données administratives du domaine de la santé, nous avons identifié une cohorte de sujets âgés de 40 ans et plus chez qui l'on a diagnostiqué, entre 1995 et 2009, les premiers symptômes de la MP. À cet égard, nous avons fait appel à une étude cas témoins pour déterminer si un certain nombre de facteurs étaient associés à la SCP dans le cas de patients atteints de la MP. Nos patients sont ainsi devenus des « cas » s'ils avaient été soumis à la SCP à n'importe quel moment 12 mois après avoir intégré notre cohorte, et ce, jusqu'au 31 décembre 2016. Nous avons aussi utilisé un modèle de régression logistique conditionnelle afin d'estimer le rapport de cotes ajusté (adjusted odds) d'une intervention de SCP en lien avec les caractéristiques évoquées ci-dessous et l'utilisation des soins de santé. Résultats: Au total, 46237 sujets atteints de la MP ont été identifiés ; de ce nombre, 543 d'entre eux $(1,2 \%)$ avaient bénéficié de la SCP. Les sujets vivant dans le nord de l'Ontario sont apparus plus susceptibles que ceux du sud de la province de bénéficier d'une telle intervention chirurgicale ( $\mathrm{RC}$ ajusté $=2,23$; IC $95 \%=1,15-4,34$ ). Cela dit, aucune variation régionale n'a été observée après avoir tenu compte de la prise de médicaments parmi les sujets plus âgés (RC ajusté $=1,04$; IC $95 \%=$ $0,26-4,21)$. Ajoutons également que les sujets vivant dans des quartiers ayant de plus fortes concentrations de minorités visibles étaient moins susceptibles d'être soumis à la SCP si on les compare à ceux vivant dans des quartiers à prédominance blanche (RC ajusté $=0,27 ;$ IC $95 \%=$ $0,16-0,46)$. Enfin, le fait d'obtenir des soins en neurologie de façon régulière et de prendre plusieurs médicaments contre la MP a été associé de façon positive à la SCP. Conclusions: Il se peut donc que toutes ces variations en lien avec la SCP reflètent des différences dans l'accès aux soins de santé mais aussi en ce qui concerne les options d'aiguillage vers des spécialistes, les comportements favorisant la santé (health-seeking behavior) ou le besoin d'une SCP. Chose certaine, des études ultérieures demeurent nécessaires afin de mieux comprendre les facteurs qui expliquent ces variations potentielles.

From the Department of Neurology, University of Pennsylvania Perelman School of Medicine, Philadelphia, PA, USA (JAGC, AWW); Department of Biostatistics, Epidemiology and Informatics, University of Pennsylvania Perelman School of Medicine, Philadelphia, PA, USA (JAGC, AWW); ICES North, Sudbury, ON, Canada (JAGC); Division of Human Sciences, Northern Ontario School of Medicine, Sudbury, ON, Canada (JAGC); ICES Western, London, ON, Canada (ML, BL, LR, SZS); Emergency Department, Health Sciences North, Sudbury, ON, Canada) (DRA, MS); Division of Clinical Sciences, Northern Ontario School of Medicine, Sudbury, ON, Canada (DRA, MS); The Edmond J Safra Program in Parkinson's Disease, Toronto Western Hospital, University of Toronto, Toronto, ON Canada (CM); Department of Neurology Translational Center of Excellence for Neuroepidemiology and Neurological Outcomes Research, University of Pennsylvania Perelman School of Medicine, Philadelphia, PA, USA (AWW); Center for Clinical Epidemiology and Biostatistics, University of Pennsylvania Perelman School of Medicine, Philadelphia, PA, USA (AWW); and Department of Psychiatry, Queen's University, ICES-Queen's, Kingston, ON, Canada (DS)

Received October 24, 2019. Final Revisions Submitted April 3, 2020. Date of Acceptance April 16, 2020.

Correspondence to: James A.G. Crispo, PhD, Perelman School of Medicine, University of Pennsylvania, Blockley Hall, 423 Guardian Drive, Office 829, Philadelphia, PA 19104, USA. Email: jcris021@uottawa.ca 
Keywords: Parkinson disease, Deep brain stimulation, Ontario, ON-Marg

doi:10.1017/cjn.2020.79

Can J Neurol Sci. 2020; 47: 642-655

\section{INTRODUCTION}

Parkinson's disease (PD) is a progressive neurodegenerative movement disorder that affects more than 40,000 Ontarians. ${ }^{1}$ There is no known cure for PD; however, the disorder may effectively be managed with medications, physical therapies, and/or deep brain stimulation (DBS) surgery. ${ }^{2-4}$ Since receiving Health Canada approval for DBS to treat patients with PD, randomized controlled trials have demonstrated that DBS is superior to existing pharmacotherapies for PD in select clinical settings and may enhance activities of daily living and quality of life. ${ }^{3,5}$

Despite DBS being effective for treating PD patients who experience non-responsive motor fluctuations or debilitating tremor, ${ }^{6}$ observational data suggest that DBS for PD is underutilized in practice and that inequalities in access to this advanced therapy exist. $^{7,8}$ Large studies of publicly insured US populations have found that women, minorities, and individuals living in low socioeconomic neighborhoods are most vulnerable to inequalities in PD care, ${ }^{9-11}$ including lower utilization of DBS. ${ }^{7,8}$ The nature of these inequalities is unclear and may represent differences in need or perceived need for DBS, barriers to accessing specialty care, health-seeking behavior, or patient preference. It is unknown if similar inequalities in access to DBS for PD exist in regions with universal coverage for medically necessary services, such as Canada. Such knowledge is crucial for future health service planning, as projected increases in PD incidence over the next two decades may exacerbate any underlying inequalities in access to the most appropriate PD care. ${ }^{12}$ This may subsequently worsen health outcomes for patients with PD and increase their associated health care costs.

The objective of our study was to examine whether sociodemographic characteristics and health care utilization were associated with undergoing DBS surgery among individuals who were diagnosed with PD between January 1, 1995, and December 31,2009 , at 40 years of age or older in Ontario, Canada. Since rural residents of Ontario oftentimes have difficulty accessing specialty care due to distance to care and service availability, ${ }^{13,14}$ we hypothesized that individuals residing in northern, more rural parts of the province would be less likely to receive DBS for PD, and that urban-rural disparities would exceed those attributable to factors such as neighborhood ethnic concentration and PD medication use.

\section{Methods}

\section{Study Design and Setting}

We conducted a case-control study within a cohort of individuals 40 years of age or older who were diagnosed with incident PD between January 1, 1995, and December 31, 2009, in Ontario, Canada. Ontario has a publicly funded single-payer health care system, which permitted us to follow our entire study population using linked health administrative datasets housed at ICES. ICES is an independent, non-profit research institute whose legal status under Ontario's health information privacy law allows it to collect and analyze health care and demographic data, without consent, for health system evaluation and improvement. The use of data for this project was authorized under section 45 of Ontario's Personal Health Information Protection Act, which does not require review by a Research Ethics Board. Our study complies with the REporting of studies Conducted using Observational Routinely collected Data (RECORD) statement ${ }^{15}$ (Supplementary Table 1).

\section{Data Sources}

We used several ICES datasets in our study, including the Canadian Institutes for Health Information Discharge Abstract Database (DAD), the National Ambulatory Care Reporting System (NACRS), the Ontario Drug Benefit (ODB) Claims, the Ontario Health Insurance Plan (OHIP) Claims Database, the Ontario Mental Health Reporting System (OMHRS), the Registered Persons Database (RPDB), and the Immigration, Refugees and Citizenship Canada Permanent Resident Database (IRCC). These datasets were linked using unique encoded identifiers and analyzed at ICES. A complete list and description of databases used for this study are provided in Supplementary Table 2.

Diagnoses and procedures examined within our study were identified via International Classification of Diseases, Ninth (ICD-9-CA) and Tenth (ICD-10-CA) Revision codes, Canadian Classification of Health Interventions (CCI) codes, Canadian Classification of Procedures (CCP) codes, and OHIP diagnostic and fee codes (Supplementary Table 3).

\section{Study Participants}

Cohort entry was defined as the earliest documented PD diagnosis between January 1, 1995, and December 31, 2009. Individuals were only included in our study if they also had a subsequent health care encounter at least 30 days later, but within 1 year, where PD was diagnosed a second time (following a validated Ontario-based parkinsonism algorithm ${ }^{16}$ adapted for PD). After identifying the earliest PD diagnosis date within the accrual period for each individual, we excluded: (1) individuals with a missing or invalid Ontario Health Card number; (2) individuals who had missing age or sex data; (3) individuals who had a recorded death date on or before cohort entry; and (4) individuals who were not residents of Ontario.

We restricted our cohort to individuals who were 40 years of age or older at the time of first PD diagnosis to avoid inclusion of younger individuals with atypical parkinsonian symptoms or other movement disorders that may have been misclassified as PD. To ensure that our cohort was comprised of individuals with incident PD, we excluded anyone with PD diagnostic codes within 5 years prior to cohort entry, as well as those with a diagnosis of secondary parkinsonism or atypical parkinsonism, or who underwent DBS surgery within 5 years prior to or within a year after cohort entry. We also excluded individuals who were long-term care residents at the time of 


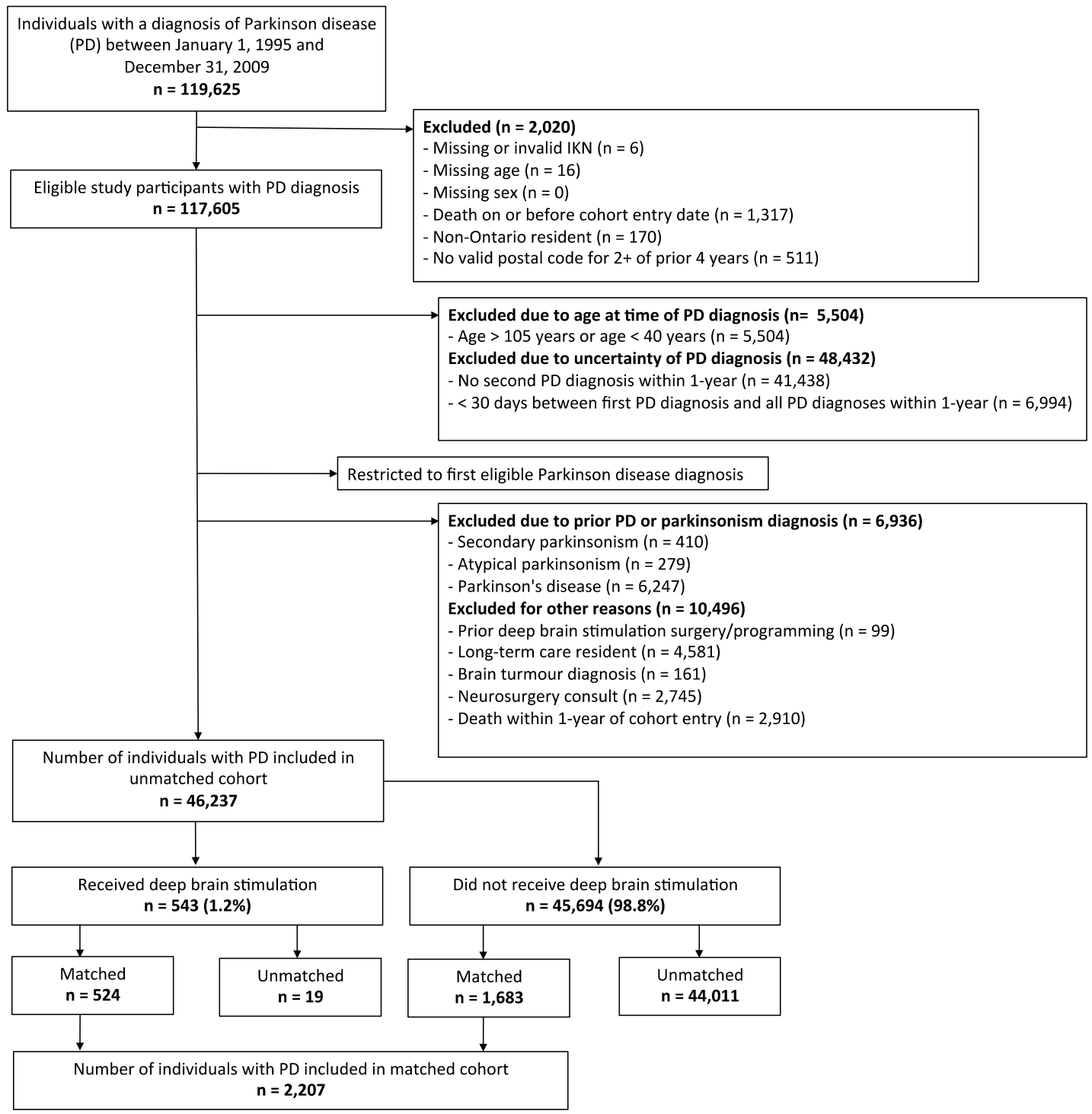

Figure 1: Cohort selection.

cohort entry. To further ensure study participants were eligible to receive $\mathrm{DBS}$ for $\mathrm{PD}$, we excluded individuals with relative contraindications for DBS: (1) individuals with a brain tumour diagnosis within 5 years prior to or within a year after cohort entry; and (2) individuals with one or more neurosurgery consults (a proxy for possible DBS surgery contraindication) within 4 years prior to or within a year after cohort entry. Lastly, we excluded anyone who died within the year after cohort entry to ensure that patients were alive at the start of follow-up.

\section{Primary Outcome and Matching}

Receipt of DBS for PD was our primary study outcome and was defined for each individual (cases) as the earliest documented date, hereafter referred to as the index date, of DBS surgery between 1 year after cohort entry to December 31, 2016 (the follow-up period).

To examine factors that may be related to receipt of DBS, a group of controls were selected from the cohort of individuals with incident PD. Pseudo index dates were randomly assigned to individuals who did not undergo DBS surgery (controls) during the study follow-up period. In instances where controls died within the follow-up period, the pseudo index date was randomly assigned between 1 year after cohort entry and the date of death.

Cases who received DBS were matched with up to four controls on patient age $( \pm 1$ year), sex, time with $P D$ at the index date ( \pm 365 days; as a marker of PD severity), and cohort entry date ( \pm 365 days). A flow chart describing participant selection is provided in Figure 1.

\section{Patient Characteristics and Health Care Utilization}

We reported the following sociodemographic characteristics at the index date for each individual: age, sex, immigration status, socioeconomic status, and health care service region. Socioeconomic status was assessed according to the Ontario Marginalization Index (ON-Marg), which is a census- and geographically 
Table 1a: Sociodemographic characteristics of DBS cases and matched PD controls

\begin{tabular}{|c|c|c|c|c|}
\hline & Total $(n=2207)$ & No DBS $(n=1683)$ & DBS $(n=524)$ & WSD \\
\hline Age (years), mean $(\mathrm{SD})^{\mathrm{a}}$ & $62.92 \pm 7.41$ & $63.17 \pm 7.39$ & $62.13 \pm 7.42$ & 0.01 \\
\hline Female, $\mathrm{n}(\%)^{\mathrm{a}}$ & $679(30.8 \%)$ & $515(30.6 \%)$ & $164(31.3 \%)$ & $<0.01$ \\
\hline Immigrant, n (\%) & $179(8.1 \%)$ & $130(7.7 \%)$ & $49(9.4 \%)$ & 0.04 \\
\hline \multicolumn{5}{|l|}{ ON-Marg: Residential instability, n (\%) } \\
\hline Quintile 1 (least marginalized) & $365(16.5 \%)$ & $266(15.8 \%)$ & $99(18.9 \%)$ & 0.08 \\
\hline Quintile 2 & $404(18.3 \%)$ & $298(17.7 \%)$ & $106(20.2 \%)$ & 0.06 \\
\hline Quintile 3 & $410(18.6 \%)$ & $310(18.4 \%)$ & $100(19.1 \%)$ & 0.03 \\
\hline Quintile 4 & $432(19.6 \%)$ & $334(19.8 \%)$ & $98(18.7 \%)$ & 0.04 \\
\hline Quintile 5 (most marginalized) & $564(25.6 \%)$ & $446(26.5 \%)$ & $118(22.5 \%)$ & 0.10 \\
\hline Missing & $32(1.4 \%)$ & $29(1.7 \%)$ & $<=5$ & \\
\hline \multicolumn{5}{|l|}{ ON-Marg: Material deprivation, n (\%) } \\
\hline Quintile 1 (least marginalized) & $475(21.5 \%)$ & $326(19.4 \%)$ & $149(28.4 \%)$ & 0.22 \\
\hline Quintile 2 & $433(19.6 \%)$ & $321(19.1 \%)$ & $112(21.4 \%)$ & 0.06 \\
\hline Quintile 3 & $425(19.3 \%)$ & $328(19.5 \%)$ & $97(18.5 \%)$ & 0.02 \\
\hline Quintile 4 & $416(18.8 \%)$ & $320(19.0 \%)$ & $96(18.3 \%)$ & 0.00 \\
\hline Quintile 5 (most marginalized) & $426(19.3 \%)$ & $359(21.3 \%)$ & $67(12.8 \%)$ & 0.26 \\
\hline Missing & $32(1.4 \%)$ & $29(1.7 \%)$ & $<=5$ & \\
\hline \multicolumn{5}{|l|}{ ON-Marg: Dependency, n (\%) } \\
\hline Quintile 1 (least marginalized) & $360(16.3 \%)$ & $277(16.5 \%)$ & $83(15.8 \%)$ & 0.03 \\
\hline Quintile 2 & $386(17.5 \%)$ & $279(16.6 \%)$ & $107(20.4 \%)$ & 0.10 \\
\hline Quintile 3 & $370(16.8 \%)$ & $280(16.6 \%)$ & $90(17.2 \%)$ & 0.00 \\
\hline Quintile 4 & $430(19.5 \%)$ & $324(19.3 \%)$ & $106(20.2 \%)$ & 0.03 \\
\hline Quintile 5 (most marginalized) & $629(28.5 \%)$ & $494(29.4 \%)$ & $135(25.8 \%)$ & 0.06 \\
\hline Missing & $32(1.4 \%)$ & $29(1.7 \%)$ & $<=5$ & \\
\hline \multicolumn{5}{|l|}{ ON-Marg: Ethnic concentration, n (\%) } \\
\hline Quintile 1 (least marginalized) & $433(19.6 \%)$ & $328(19.5 \%)$ & $105(20.0 \%)$ & 0.01 \\
\hline Quintile 2 & $462(20.9 \%)$ & $354(21.0 \%)$ & $108(20.6 \%)$ & 0.00 \\
\hline Quintile 3 & $416(18.8 \%)$ & $304(18.1 \%)$ & $112(21.4 \%)$ & 0.09 \\
\hline Quintile 4 & $409(18.5 \%)$ & $308(18.3 \%)$ & $101(19.3 \%)$ & 0.03 \\
\hline Quintile 5 (most marginalized) & $455(20.6 \%)$ & $360(21.4 \%)$ & $95(18.1 \%)$ & 0.10 \\
\hline Missing & $32(1.4 \%)$ & $29(1.7 \%)$ & $<=5$ & \\
\hline \multicolumn{5}{|l|}{ Health care service region (LHIN), n (\%) } \\
\hline Erie St. Clair (1) & $133(6.0 \%)$ & $103(6.1 \%)$ & $30(5.7 \%)$ & 0.03 \\
\hline South West (2) & $221(10.0 \%)$ & $157(9.3 \%)$ & $64(12.2 \%)$ & 0.10 \\
\hline Waterloo Wellington (3) & $110(5.0 \%)$ & $81(4.8 \%)$ & $29(5.5 \%)$ & 0.03 \\
\hline Hamilton Niagara Haldimand Brant (4) & $233(10.6 \%)$ & $179(10.6 \%)$ & $54(10.3 \%)$ & 0.01 \\
\hline Central West (5) & $113(5.1 \%)$ & $92(5.5 \%)$ & $21(4.0 \%)$ & 0.10 \\
\hline Mississauga Halton (6) & $164(7.4 \%)$ & $120(7.1 \%)$ & $44(8.4 \%)$ & 0.05 \\
\hline Toronto Central (7) & $189(8.6 \%)$ & $143(8.5 \%)$ & $46(8.8 \%)$ & 0.02 \\
\hline Central (8) & $226(10.2 \%)$ & $171(10.2 \%)$ & $55(10.5 \%)$ & 0.03 \\
\hline Central East (9) & $241(10.9 \%)$ & $188(11.2 \%)$ & $53(10.1 \%)$ & 0.03 \\
\hline South East (10) & $98(4.4 \%)$ & $75(4.5 \%)$ & $23(4.4 \%)$ & 0.01 \\
\hline Champlain (11) & $254(11.5 \%)$ & $204(12.1 \%)$ & $50(9.5 \%)$ & 0.11 \\
\hline North Simcoe Muskoka (12) & $77(3.5 \%)$ & $61(3.6 \%)$ & $16(3.1 \%)$ & 0.03 \\
\hline North East (13) & $98(4.4 \%)$ & $73(4.3 \%)$ & $25(4.8 \%)$ & 0.03 \\
\hline North West (14) & $35(1.6 \%)$ & $22(1.3 \%)$ & $13(2.5 \%)$ & 0.10 \\
\hline Missing & $15(0.7 \%)$ & $14(0.8 \%)$ & $<=5$ & \\
\hline
\end{tabular}


Table 1a: (Continued)

\begin{tabular}{l|c|c|c|c}
\hline & Total $(\mathbf{n}=\mathbf{2 2 0 7})$ & No DBS $(\mathbf{n}=\mathbf{1 6 8 3})$ & DBS $(\mathbf{n}=\mathbf{5 2 4})$ & WSD \\
\hline Grouped regions, $\mathrm{n}(\%)^{\mathrm{b}}$ & & & & \\
\hline Southern Ontario (all southern LHINs) & $2059(93.3 \%)$ & $1574(93.5 \%)$ & $485(92.6 \%)$ & 0.08 \\
\hline Northern Ontario (North East and North West) & $133(6.0 \%)$ & $95(5.6 \%)$ & $38(7.3 \%)$ & \\
\hline Missing & $15(0.7 \%)$ & $14(0.8 \%)$ & $<=5$ & \\
\hline
\end{tabular}

DBS = deep brain stimulation; LHIN = Local Health Integration Network; ON-Marg = Ontario Marginalization Index; PD = Parkinson's disease; $\mathrm{SD}=$ standard deviation; $\mathrm{WSD}=$ weighted standardized difference.

${ }^{\text {a }}$ Covariate used in matching of controls to cases.

bontario's three DBS surgery sites are all located in Southern Ontario.

based index that aims to (1) show differences in marginalization between areas and (2) understand inequalities in various measures of health and social well-being, either between population groups or between geographical areas. ${ }^{17}$ The ON-Marg domains (residential instability, material deprivation, dependency, and ethnic concentration) were assessed using the ON-Marg data year $(2001,2006,2011$, or 2016) closest to each patient's index date. Health care service regions were defined according to Ontario's Local Health Integration Network (LHIN) boundaries [individually and grouped as northern (North East and North West) and southern (all others) regions; Supplementary Figure 1)]. Ontario's LHINs are regional health authorities responsible for planning, integrating, and funding health care services within the province. ${ }^{18}$

Comorbidities were measured during the prior 2 years (excluding index date) and reported using the Johns Hopkins $\mathrm{ACG}^{\circledR}$ System (version 10) Aggregated Diagnosis Groups (ADGs). ${ }^{19}$ The presence of dementia was assessed during the same period. Health care for psychosis, stroke, suicide attempt, and injurious falls was similarly measured during the 5 years prior to index date.

We further collected information on individual health care utilization, including the number of encounters and emergency department, psychiatrist, geriatrician, and neurologist visits within the 2-year period prior to index date. Thresholds for categorical health care utilization variables were determined $a$ priori based on the distribution of related data and with input from collaborating physicians. Primary care access was assessed by determining whether study participants were rostered to a primary care physician at their index date.

\section{Primary Analyses}

Descriptive statistics were used to describe the sociodemographic characteristics, health care utilization, comorbidities and injuries, and frequency of DBS surgery within the unmatched and matched groups. A weighted standardized difference was used to assess variations in measured characteristics between matched cases and controls, with differences of $>0.10$ considered to indicate a significant imbalance in variables. We separately assessed the association between each patient characteristic of interest (including health care service region, ON-Marg domains, health care utilization by specialty, and having a primary care physician) and receipt of DBS surgery using a conditional logistic regression model to estimate the odds of DBS surgery for each factor while adjusting for: all ON-Marg domains (residential instability, material deprivation, dependency, and ethnic concentration); overall illness (ADGs); prior diagnosis of dementia and psychosis; prior psychiatrist, geriatrician, and neurologist visits; and having a primary care physician. These covariates were selected because they either remained imbalanced between case and control groups after matching and/or were $a$ priori (such as ON-Marg domains and ADGs) believed to confound modeled relationships based on clinical understanding. Matched casecontrol sets with missing ON-Marg data for the case or any control were excluded from our analyses (complete case analyses). We used an alpha of 0.05 as the threshold for significance. Cell sizes $\leq 5$ were suppressed to protect patient privacy. Adjustments for multiple comparisons were not made since our analyses were deemed a priori to be exploratory in nature. All analyses were completed using SAS v9.4 (SAS Institute Inc., Cary, NC, USA).

\section{Subgroup Analyses: Older Adults and Medication Use}

Since medication responses may confound associations between patient factors, care patterns, and receipt of DBS surgery, we performed subgroup analyses to examine whether estimated effects in our primary analyses were similar after accounting for the use of PD medications by older adults. The majority of medications, including those commonly used to treat PD, are publicly funded for Ontarians who are 65 years of age and older. To allow for a 2-year lookback period, we examined prior PD medication use among a subset of the matched cohort who were 67 years of age or older at the index date. Prescriptions for medications within the following classes were examined: levodopa (levodopa, levodopa-carbidopa, levodopa-carbidopaentacapone), non-ergot dopamine agonists (pramipexole, ropinirole), ergot dopamine agonists (bromocriptine, pergolide), monoamine oxidase B (MAO-B) inhibitors (selegiline, rasagiline), catechol-O-methyltransferase (COMT) inhibitors (tolcapone, entacapone, levodopa-carbidopa-entacapone), PD anticholinergics (benztropine, biperiden, procyclidine, trihexyphenidyl), and amantadine (amantadine). The total number of distinct PD medication classes used by each individual within the 2-year lookback period was computed and categorized as: $0,1-2,3-4$, and 5+. Lists of individual Drug Identification Numbers (DINs) used to define individual medications and medication classes are provided in Supplementary Table 4.

Primary analyses were repeated in the subgroup that was $67+$ years of age at the index date with and without the addition of indicators for PD medication class use in the previous 2 years 
Table 1b: Clinical and provider characteristics of DBS cases and matched PD controls

\begin{tabular}{|c|c|c|c|c|}
\hline & Total $(n=2207)$ & No DBS $(n=1683)$ & DBS $(\mathbf{n}=\mathbf{5 2 4})$ & WSD \\
\hline \multicolumn{5}{|l|}{ PD diagnosis and duration } \\
\hline \multicolumn{5}{|c|}{ Year of PD diagnosis (cohort entry), $\mathrm{n}(\%)^{\mathrm{a}}$} \\
\hline 1995 & $444(20.1 \%)$ & $339(20.1 \%)$ & $105(20.0 \%)$ & 0.00 \\
\hline 1996 & $105(4.8 \%)$ & $79(4.7 \%)$ & $26(5.0 \%)$ & 0.01 \\
\hline 1997 & $96(4.3 \%)$ & $70(4.2 \%)$ & $26(5.0 \%)$ & 0.01 \\
\hline 1998 & $96(4.3 \%)$ & $72(4.3 \%)$ & $24(4.6 \%)$ & 0.03 \\
\hline 1999 & $126(5.7 \%)$ & $95(5.6 \%)$ & $31(5.9 \%)$ & 0.03 \\
\hline 2000 & $132(6.0 \%)$ & $103(6.1 \%)$ & $29(5.5 \%)$ & 0.02 \\
\hline 2001 & $104(4.7 \%)$ & $71(4.2 \%)$ & $33(6.3 \%)$ & 0.07 \\
\hline 2002 & $133(6.0 \%)$ & $104(6.2 \%)$ & $29(5.5 \%)$ & 0.11 \\
\hline 2003 & $150(6.8 \%)$ & $109(6.5 \%)$ & $41(7.8 \%)$ & 0.07 \\
\hline 2004 & $124(5.6 \%)$ & $92(5.5 \%)$ & $32(6.1 \%)$ & 0.02 \\
\hline 2005 & $175(7.9 \%)$ & $140(8.3 \%)$ & $35(6.7 \%)$ & 0.07 \\
\hline 2006 & $178(8.1 \%)$ & $139(8.3 \%)$ & $39(7.4 \%)$ & 0.01 \\
\hline 2007 & $119(5.4 \%)$ & $91(5.4 \%)$ & $28(5.3 \%)$ & 0.03 \\
\hline 2008 & $162(7.3 \%)$ & $128(7.6 \%)$ & $34(6.5 \%)$ & 0.00 \\
\hline 2009 & $63(2.9 \%)$ & $51(3.0 \%)$ & $12(2.3 \%)$ & 0.02 \\
\hline Time with PD (years), mean (SD) ${ }^{\mathrm{a}}$ & $9.00 \pm 3.63$ & $8.89 \pm 3.63$ & $9.34 \pm 3.64$ & 0.01 \\
\hline \multicolumn{5}{|l|}{ Comorbidities in previous 2 years } \\
\hline \multicolumn{5}{|l|}{ ADGs, n (\%) } \\
\hline 0 & $53(2.4 \%)$ & $53(3.1 \%)$ & $0(0.0 \%)$ & 0.49 \\
\hline $1-2$ & $152(6.9 \%)$ & $140(8.3 \%)$ & $12(2.3 \%)$ & 0.42 \\
\hline $3-4$ & $331(15.0 \%)$ & $261(15.5 \%)$ & $70(13.4 \%)$ & 0.09 \\
\hline $5-6$ & $445(20.2 \%)$ & $334(19.8 \%)$ & $111(21.2 \%)$ & 0.02 \\
\hline $7+$ & $1,226(55.6 \%)$ & $895(53.2 \%)$ & $331(63.2 \%)$ & 0.30 \\
\hline Dementia, n (\%) & $245(11.1 \%)$ & $216(12.8 \%)$ & $29(5.5 \%)$ & 0.31 \\
\hline Psychosis, n (\%) & $295(13.4 \%)$ & $245(14.6 \%)$ & $50(9.5 \%)$ & 0.21 \\
\hline Stroke, n $(\%)$ & $159(7.2 \%)$ & $132(7.8 \%)$ & $27(5.2 \%)$ & 0.09 \\
\hline \multicolumn{5}{|l|}{ Injuries in previous 5 years, $\mathrm{n}(\%)$} \\
\hline Suicide attempt & $16(0.7 \%)$ & $10(0.6 \%)$ & $6(1.1 \%)$ & 0.06 \\
\hline Fall & $402(18.2 \%)$ & $301(17.9 \%)$ & $101(19.3 \%)$ & 0.04 \\
\hline \multicolumn{5}{|c|}{ Health care utilization in previous 2 years, $\mathrm{n}(\%)$} \\
\hline \multicolumn{5}{|l|}{ All health care visits } \\
\hline $30+$ visits & $1195(54.1 \%)$ & $789(46.9 \%)$ & $406(77.5 \%)$ & 0.91 \\
\hline$<30$ visits & $1012(45.9 \%)$ & $894(53.1 \%)$ & $118(22.5 \%)$ & \\
\hline \multicolumn{5}{|l|}{ Emergency department visits } \\
\hline Any visit & $1005(45.5 \%)$ & $750(44.6 \%)$ & $255(48.7 \%)$ & 0.10 \\
\hline No visit & $1202(54.5 \%)$ & $933(55.4 \%)$ & $269(51.3 \%)$ & \\
\hline \multicolumn{5}{|l|}{ Psychiatrist visits } \\
\hline Any visit & $610(27.6 \%)$ & $285(16.9 \%)$ & $325(62.0 \%)$ & 1.19 \\
\hline No visit & $1597(72.4 \%)$ & $1398(83.1 \%)$ & $199(38.0 \%)$ & \\
\hline \multicolumn{5}{|l|}{ Geriatrician visits } \\
\hline Any visit & $123(5.6 \%)$ & $108(6.4 \%)$ & $15(2.9 \%)$ & 0.22 \\
\hline No visit & $2084(94.4 \%)$ & $1575(93.6 \%)$ & $509(97.1 \%)$ & \\
\hline
\end{tabular}


Table 1b: (Continued)

\begin{tabular}{l|c|c|c|c}
\hline & Total $(\mathbf{n}=\mathbf{2 2 0 7})$ & No DBS $(\mathbf{n}=\mathbf{1 6 8 3})$ & DBS $(\mathbf{n = 5 2 4})$ & WSD \\
\hline Neurologist visits & & & $459(87.6 \%)$ & \\
\hline $4+$ visits & $1151(52.2 \%)$ & $692(41.1 \%)$ & $<=65$ & 1.59 \\
\hline $1-3$ visits & $470(21.3 \%)$ & $<=410$ & $<=5$ & 0.42 \\
\hline No visit & $586(26.6 \%)$ & $<=585$ & & 1.80 \\
\hline Primary care physician status & & & $395(75.4 \%)$ & \\
\hline Rostered to a primary care Physician, $\mathrm{n}(\%)$ & $1593(72.2 \%)$ & $1198(71.2 \%)$ & 0.11 \\
\hline
\end{tabular}

$\mathrm{ADG}=$ Aggregated Diagnosis Group; DBS = deep brain stimulation; LHIN = Local Health Integration Network; PD = Parkinson's disease; SD = standard deviation; WSD $=$ weighted standardized difference.

${ }^{\mathrm{a} C}$ Covariate used in matching of controls to cases.

[dichotomous variables: any levodopa, non-ergot dopamine agonist, ergot dopamine agonist, MAO-B inhibitor, COMT inhibitor, anticholinergic for $\mathrm{PD}$, and amantadine] to our regression models.

\section{Sensitivity Analyses}

To minimize any bias and loss of precision in our results due to missing ON-Marg data, we repeated our primary and subgroup analyses with all missing ON-Marg domain data imputed as quintile 3 .

\section{Data Availability Statement}

The dataset from this study is held securely in coded form at ICES. While data sharing agreements prohibit ICES from making the dataset publicly available, access may be granted to those who meet pre-specified criteria for confidential access, available at www.ices.on.ca/DAS. The full dataset creation plan and underlying analytic code are available from the authors upon request, understanding that the computer programs may rely upon coding templates or macros that are unique to ICES and are therefore either inaccessible or may require modification.

\section{Results}

\section{Cohort Characteristics}

Prior to matching, we found 46,237 individuals diagnosed with incident PD and eligible for inclusion in our study cohort between January 1, 1995, and December 31, 2009 (Figure 1). During the study follow-up period (1 year after cohort entry date to December 31, 2016), $543(1.2 \%)$ of these patients underwent DBS surgery. The majority of DBS surgeries within our cohort were performed between 2010 and 2016 (62.4\%), with $23.6 \%$ and $14.0 \%$ performed between 2004-2009 and 1996-2003, respectively. In the unmatched sample, more male patients were treated with DBS compared to female patients $(68.0 \%$ vs. $32.0 \%)$ and the mean time from PD diagnosis to DBS surgery was $9.5 \pm 3.7$ years. The majority of individuals (75.5\%) undergoing DBS surgery were rostered to a family physician at the time of surgery. Baseline characteristics of the unmatched PD study cohort are available in Supplementary Tables 5 and 6.

A total of 524 DBS surgery cases were matched with 1683 PD patients who did not undergo DBS surgery. Overall, weighted standardized differences show that cases and controls had similar characteristics after matching (Table 1a and 1b).

\section{Factors Associated with DBS Surgery}

After adjustment, a number of factors were associated with receipt of DBS surgery for PD (Table 2). Individuals residing in Northern Ontario were twice as likely to receive DBS surgery than those living in Southern Ontario (adjusted odds ratio (AOR) $=2.23,95 \%$ confidence interval $(\mathrm{CI})=1.15-4.34$ ). Compared to patients living in neighborhoods with the lowest concentration of recent immigrants and visible minorities (quintile 1), individuals living in neighborhoods with higher concentrations of recent immigrants and visible minorities were significantly less likely to receive DBS surgery (quintile 2 : $\mathrm{AOR}=0.59,95 \% \mathrm{CI}=0.38-$ 0.92; quintile 3: $\mathrm{AOR}=0.61,95 \% \mathrm{CI}=0.39-0.97$; quintile 4: $\mathrm{AOR}=0.48,95 \% \mathrm{CI}=0.29-0.78$; quintile $5: \mathrm{AOR}=0.27,95 \%$ $\mathrm{CI}=0.16-0.46$ ). Relative to patients with 30 or more total health care encounters in the 2 years prior to the index date, patients with fewer health care visits were significantly less likely to undergo DBS surgery $(<30$ visits vs. $30+$ visits: $A O R=0.28,95 \%$ $\mathrm{CI}=0.20-0.41)$. The same was found for patients with fewer psychiatrist (no visit vs. any visit: $\mathrm{AOR}=0.11,95 \% \mathrm{CI}=0.08-$ 0.15 ) and neurologist ( $1-3$ visits vs. $4+$ visits: $A O R=0.21,95 \%$ $\mathrm{CI}=0.14-0.31)$ consults in the previous 2 years. Conversely, a negative association between geriatrician visits and receipt of DBS surgery was observed (no visit vs. any visit: $\mathrm{AOR}=2.12$, $95 \% \mathrm{CI}=1.05-4.28$ ).

\section{Subgroup Analyses}

There were 747 patients (33.8\% of matched cohort; 155 DBS cases, 592 controls) included in our subgroup analyses of patients $67+$ years of age. Among these patients, individuals treated with DBS were more likely than controls to have been treated with medications from individual PD medication classes in the previous 2-year period (use of >2 PD medication classes: $63.2 \%$ DBS vs. $27.6 \%$ no DBS). This includes use of any levodopa ( $92.3 \%$ vs. $70.4 \%$ ), non-ergot dopamine agonists (56.1\% vs. $26.2 \%)$, ergot dopamine agonist (11.6\% vs. $6.1 \%)$, MAO-B inhibitor $(12.9 \%$ vs. $10.5 \%)$, COMT inhibitor ( $38.1 \%$ vs. $16.0 \%)$, anticholinergic ( $7.7 \%$ vs. $5.7 \%$ ), or amantadine ( $45.2 \%$ vs. $17.2 \%)$. The complete description of medication use is available in Table 3.

We did not observe any geographic differences in the likelihood of receiving DBS in our subgroup analyses of patients $67+$ 
Table 2: Association between select characteristics and DBS surgery

\begin{tabular}{|c|c|c|}
\hline & $\mathbf{A O R}^{\mathrm{ab}}(95 \% \mathrm{CI})$ & P value \\
\hline \multicolumn{3}{|l|}{ Patient characteristics } \\
\hline \multicolumn{3}{|l|}{ Immigrant to Canada } \\
\hline No & Reference & - \\
\hline Yes & $1.22(0.68-2.19)$ & 0.50 \\
\hline \multicolumn{3}{|l|}{ ON-Marg: Residential instability } \\
\hline Quintile 1 (least marginalized) & Reference & - \\
\hline Quintile 2 & $1.01(0.63-1.62)$ & 0.97 \\
\hline Quintile 3 & $1.15(0.68-1.95)$ & 0.59 \\
\hline Quintile 4 & $0.96(0.57-1.60)$ & 0.87 \\
\hline Quintile 5 (most marginalized) & $1.22(0.72-2.07)$ & 0.46 \\
\hline \multicolumn{3}{|l|}{ ON-Marg: Material deprivation } \\
\hline Quintile 1 (least marginalized) & Reference & - \\
\hline Quintile 2 & $0.89(0.58-1.35)$ & 0.58 \\
\hline Quintile 3 & $0.90(0.57-1.42)$ & 0.65 \\
\hline Quintile 4 & $0.96(0.60-1.53)$ & 0.86 \\
\hline Quintile 5 (most marginalized) & $0.77(0.45-1.33)$ & 0.34 \\
\hline \multicolumn{3}{|l|}{ ON-Marg: Dependency } \\
\hline Quintile 1 (least marginalized) & Reference & \\
\hline Quintile 2 & $1.55(0.92-2.60)$ & 0.10 \\
\hline Quintile 3 & $1.21(0.72-2.04)$ & 0.47 \\
\hline Quintile 4 & $1.06(0.63-1.80)$ & 0.81 \\
\hline Quintile 5 (most marginalized) & $0.80(0.47-1.34)$ & 0.39 \\
\hline \multicolumn{3}{|l|}{ ON-Marg: Ethnic concentration } \\
\hline Quintile 1 (least marginalized) & Reference & - \\
\hline Quintile 2 & $0.59(0.38-0.92)$ & 0.02 \\
\hline Quintile 3 & $0.61(0.39-0.97)$ & 0.04 \\
\hline Quintile 4 & $0.48(0.29-0.78)$ & $<0.01$ \\
\hline Quintile 5 (most marginalized) & $0.27(0.16-0.46)$ & $<0.01$ \\
\hline \multicolumn{3}{|l|}{ Health care service region (LHIN) } \\
\hline Toronto Central (7) & Reference & - \\
\hline Erie St. Clair (1) & $3.94(1.74-8.93)$ & $<0.01$ \\
\hline South West (2) & $4.90(2.31-10.39)$ & $<0.01$ \\
\hline Waterloo Wellington (3) & $2.18(0.92-5.17)$ & 0.08 \\
\hline Hamilton Niagara Haldimand Brant (4) & $1.42(0.66-3.07)$ & 0.37 \\
\hline Central West (5) & $0.76(0.29-2.00)$ & 0.57 \\
\hline Mississauga Halton (6) & $0.87(0.39-1.94)$ & 0.73 \\
\hline Central (8) & $1.00(0.47-2.13)$ & 0.99 \\
\hline Central East (9) & $1.06(0.49-2.31)$ & 0.87 \\
\hline South East (10) & $1.06(0.38-2.94)$ & 0.92 \\
\hline Champlain (11) & $1.13(0.52-2.44)$ & 0.75 \\
\hline North Simcoe Muskoka (12) & $0.79(0.27-2.32)$ & 0.66 \\
\hline North East (13) & $2.09(0.76-5.79)$ & 0.15 \\
\hline North West (14) & $24.38(6.06-98.04)$ & $<0.01$ \\
\hline
\end{tabular}

Table 2: (Continued)

\begin{tabular}{|c|c|c|}
\hline & $\mathrm{AOR}^{\mathrm{ab}}(95 \% \mathrm{CI})$ & $P$ value \\
\hline \multicolumn{3}{|l|}{ Grouped Regions $^{\mathrm{c}}$} \\
\hline Southern Ontario (all southern LHINs) & Reference & - \\
\hline $\begin{array}{l}\text { Northern Ontario (North East and North } \\
\text { West) }\end{array}$ & $2.23(1.15-4.34)$ & 0.02 \\
\hline \multicolumn{3}{|l|}{ Health care utilization in previous 2 years } \\
\hline \multicolumn{3}{|l|}{ All health care visits } \\
\hline $30+$ visits & Reference & - \\
\hline$<30$ visits & $0.28(0.20-0.41)$ & $<0.01$ \\
\hline \multicolumn{3}{|l|}{ Emergency department visits } \\
\hline Any visit & Reference & - \\
\hline No visit & $0.92(0.67-1.26)$ & 0.59 \\
\hline \multicolumn{3}{|l|}{ Psychiatrist visits } \\
\hline Any visit & Reference & - \\
\hline No visit & $0.11(0.08-0.15)$ & $<0.01$ \\
\hline \multicolumn{3}{|l|}{ Geriatrician visits } \\
\hline Any visit & Reference & - \\
\hline No visit & $2.12(1.05-4.28)$ & 0.03 \\
\hline \multicolumn{3}{|l|}{ Neurologist visits } \\
\hline $4+$ visits & Reference & - \\
\hline $1-3$ visits & $0.21(0.14-0.31)$ & $<0.01$ \\
\hline No visit & $0.01(0.00-0.02)$ & $<0.01$ \\
\hline \multicolumn{3}{|l|}{ Rostered to a primary care physician } \\
\hline Yes & Reference & - \\
\hline No & $1.02(0.65-1.60)$ & 0.91 \\
\hline
\end{tabular}

$\mathrm{AOR}=$ adjusted odds ratio; $\mathrm{CI}=$ confidence interval; $\mathrm{LHIN}=$ Local Health Integration Network; ON-Marg = Ontario Marginalization Index; $\mathrm{PD}=$ Parkinson's disease

a2166 patients included in analyses (521 DBS cases and 1645 controls). ${ }^{\mathrm{b}}$ Adjusted for all domains of the ON-Marg (residential instability, material deprivation, dependency, and ethnic concentration); overall illness (ADGs); diagnoses of dementia and psychosis; number of prior psychiatrist, geriatrician, and neurologist visits; and family physician status.

'Ontario's three DBS surgery sites are all located in Southern Ontario.

years of age, including those that accounted for PD medication use (Table 4). Similarly, the negative association between prior geriatrician visits and receipt of DBS surgery observed in our primary analysis was attenuated in our subgroup (no visit vs. any visit: $\mathrm{AOR}=2.27,95 \% \mathrm{CI}=0.77-6.69)$. There were minimal changes in the magnitude and direction of estimated effects for other characteristics examined in our primary analyses after taking PD medication use into consideration. Compared to patients treated with fewer PD medication classes in the previous 2 years, those who used a greater number of PD medications were more likely to undergo DBS surgery (5+ vs. $0-2$ PD medication classes: $\mathrm{AOR}=4.77,95 \% \mathrm{CI}=2.01-11.33$ ). 
Table 3: Medication use among individuals age 67+ years at index date

\begin{tabular}{|c|c|c|c|c|c|}
\hline & & Total $(n=747)$ & No DBS $(n=592)$ & DBS $(n=155)$ & \\
\hline Medication class & Medication name & n $(\%)$ & n $(\%)$ & n $(\%)$ & WSD \\
\hline \multirow[t]{4}{*}{ Levodopa } & Any levodopa & $560(75.0 \%)$ & $417(70.4 \%)$ & $143(92.3 \%)$ & 0.89 \\
\hline & Levodopa & $52(7.0 \%)$ & $41(6.9 \%)$ & $11(7.1 \%)$ & 0.02 \\
\hline & Levodopa-Carbidopa & $527(70.5 \%)$ & $391(66.0 \%)$ & $136(87.7 \%)$ & 0.77 \\
\hline & $\begin{array}{l}\text { Levodopa-Carbidopa- } \\
\text { Entacapone }\end{array}$ & $41(5.5 \%)$ & $25(4.2 \%)$ & $16(10.3 \%)$ & 0.28 \\
\hline \multirow[t]{3}{*}{ Non-ergot dopamine agonist } & $\begin{array}{l}\text { Any non-ergot dopamine } \\
\text { agonist }\end{array}$ & $242(32.4 \%)$ & $155(26.2 \%)$ & $87(56.1 \%)$ & 0.76 \\
\hline & Pramipexole & $183(24.5 \%)$ & $125(21.1 \%)$ & $58(37.4 \%)$ & 0.43 \\
\hline & Ropinirole & $64(8.6 \%)$ & $34(5.7 \%)$ & $30(19.4 \%)$ & 0.46 \\
\hline \multirow[t]{3}{*}{ Ergot dopamine agonists ${ }^{\mathrm{a}}$} & Any ergot dopamine agonist & $54(7.2 \%)$ & $36(6.1 \%)$ & $18(11.6 \%)$ & 0.24 \\
\hline & Bromocriptine & $22(2.9 \%)$ & $14(2.4 \%)$ & $8(5.2 \%)$ & 0.18 \\
\hline & Pergolide & $36(4.8 \%)$ & $23(3.9 \%)$ & $13(8.4 \%)$ & 0.23 \\
\hline \multirow[t]{3}{*}{ MAO-B inhibitors } & Any MAO-B inhibitor & $82(11.0 \%)$ & $62(10.5 \%)$ & $20(12.9 \%)$ & 0.10 \\
\hline & Selegiline & $67(9.0 \%)$ & $51(8.6 \%)$ & $16(10.3 \%)$ & 0.08 \\
\hline & Rasagiline & $<=20$ & $12(2.0 \%)$ & $<=5$ & 0.06 \\
\hline \multirow[t]{3}{*}{ COMT inhibitors } & Any COMT inhibitor & $154(20.6 \%)$ & $95(16.0 \%)$ & $59(38.1 \%)$ & 0.59 \\
\hline & Tolcapone & $<=5$ & $<=5$ & $0(0.0 \%)$ & 0.11 \\
\hline & Entacapone & $153(20.5 \%)$ & $94(15.9 \%)$ & $59(38.1 \%)$ & 0.59 \\
\hline \multirow[t]{4}{*}{ Anticholinergics ${ }^{\mathrm{b}}$} & Any anticholinergic for PD & $46(6.2 \%)$ & $34(5.7 \%)$ & $12(7.7 \%)$ & 0.11 \\
\hline & Benztropine & $<=15$ & $10(1.7 \%)$ & $<=5$ & 0.03 \\
\hline & Procyclidine & $<=5$ & $<=5$ & $<=5$ & 0.07 \\
\hline & Trihexyphidyl & $33(4.4 \%)$ & $24(4.1 \%)$ & $9(5.8 \%)$ & 0.11 \\
\hline Amantadine & Amantadine & $172(23.0 \%)$ & $102(17.2 \%)$ & $70(45.2 \%)$ & 0.71 \\
\hline \multicolumn{6}{|c|}{ Number of PD medication classes } \\
\hline 0 & - & $161(21.6 \%)$ & $153(25.8 \%)$ & $8(5.2 \%)$ & 0.96 \\
\hline $1-2$ & - & $325(43.5 \%)$ & $276(46.6 \%)$ & $49(31.6 \%)$ & 0.37 \\
\hline $3-4$ & - & $187(25.0 \%)$ & $123(20.8 \%)$ & $64(41.3 \%)$ & 0.55 \\
\hline $5+$ & - & $74(9.9 \%)$ & $40(6.8 \%)$ & $34(21.9 \%)$ & 0.48 \\
\hline
\end{tabular}

$\mathrm{COMT}=$ catechol-O-methyltransferase; $\mathrm{DBS}=$ deep brain stimulation; MAO-B = monoamine oxidase $\mathrm{B}$; WSD = weighted standardized difference.

${ }^{\mathrm{a}}$ No documented cabergoline use.

${ }^{\mathrm{b}}$ No documented biperiden use.

\section{Sensitivity Analyses}

ON-Marg data were missing for a total of $32(1.4 \%)$ patients in our matched cohort (Table 1a). Repeating our primary and subgroup models with missing ON-Marg domain data imputed as quintile 3 had little to no effect on our estimated associations (Supplementary Tables 7 and 8).

\section{Discussion}

Compared to best medical therapy, DBS has proven to be a safe and effective intervention for the treatment of severe motor complications in PD. Despite this, DBS surgery remains underutilized and there are limited data on factors associated with its use. ${ }^{7,8}$ We used population-level data from Ontario, Canada, to examine characteristics associated with receiving DBS surgery for PD. Contrary to our hypothesis, individuals residing in the most northern, rural parts of the province were not less likely than southern dwelling patients to receive DBS surgery for PD. In our primary analyses, northern patients were more likely than southern patients to receive DBS surgery. However, regional differences in the use of DBS for PD were not observed in our subgroup analyses of patients $67+$ years of age, including those that accounted for prior use of PD medications. Secondary findings include: (1) patients living in neighborhoods with the highest concentration of recent immigrants and visible minorities were significantly less likely to receive DBS surgery compared to patients living in predominantly white neighborhoods; (2) patients with fewer total health care visits and those with fewer neurologist consults over the previous 2 years were less likely to undergo DBS surgery than patients with a greater number of health care visits during the same period; and (3) compared to patients treated with fewer PD medication classes 
Table 4: Association between select characteristics and DBS surgery for individuals 67+ years of age at index date

\begin{tabular}{|c|c|c|c|c|}
\hline & $\operatorname{AOR}(95 \% \mathrm{CI})^{\mathrm{ab}}$ & $P$ value & $\operatorname{AOR}(95 \% \mathrm{CI})^{\mathrm{ac}}$ & $P$ value \\
\hline \multicolumn{5}{|l|}{ Patient characteristics } \\
\hline \multicolumn{5}{|l|}{ Immigrant to Canada } \\
\hline No & Reference & - & Reference & - \\
\hline Yes & $0.93(0.20-4.37)$ & 0.93 & $1.18(0.24-5.69)$ & 0.84 \\
\hline \multicolumn{5}{|l|}{ ON-Marg: Residential instability } \\
\hline Quintile 1 (least marginalized) & Reference & - & Reference & - \\
\hline Quintile 2 & $1.06(0.45-2.48)$ & 0.90 & $1.11(0.45-2.74)$ & 0.81 \\
\hline Quintile 3 & $0.73(0.27-1.98)$ & 0.54 & $0.69(0.23-2.08)$ & 0.51 \\
\hline Quintile 4 & $0.38(0.14-1.03)$ & 0.06 & $0.33(0.11-0.95)$ & 0.04 \\
\hline Quintile 5 (most marginalized) & $1.30(0.49-3.39)$ & 0.60 & $1.27(0.46-3.53)$ & 0.64 \\
\hline \multicolumn{5}{|l|}{ ON-Marg: Material deprivation } \\
\hline Quintile 1 (least marginalized) & Reference & - & Reference & - \\
\hline Quintile 2 & $0.94(0.44-2.01)$ & 0.87 & $0.87(0.38-1.95)$ & 0.73 \\
\hline Quintile 3 & $0.83(0.37-1.89)$ & 0.66 & $0.78(0.34-1.79)$ & 0.57 \\
\hline Quintile 4 & $0.50(0.20-1.28)$ & 0.15 & $0.56(0.21-1.47)$ & 0.24 \\
\hline Quintile 5 (most marginalized) & $0.89(0.31-2.50)$ & 0.82 & $1.02(0.35-2.94)$ & 0.97 \\
\hline \multicolumn{5}{|l|}{ ON-Marg: Dependency } \\
\hline Quintile 1 (least marginalized) & Reference & - & Reference & - \\
\hline Quintile 2 & $1.33(0.49-3.58)$ & 0.58 & $1.04(0.39-2.80)$ & 0.94 \\
\hline Quintile 3 & $0.82(0.29-2.29)$ & 0.70 & $0.54(0.19-1.59)$ & 0.27 \\
\hline Quintile 4 & $0.85(0.32-2.23)$ & 0.74 & $0.74(0.28-1.97)$ & 0.54 \\
\hline Quintile 5 (most marginalized) & $0.48(0.18-1.28)$ & 0.14 & $0.41(0.15-1.11)$ & 0.08 \\
\hline \multicolumn{5}{|l|}{ ON-Marg: Ethnic concentration } \\
\hline Quintile 1 (least marginalized) & Reference & - & Reference & - \\
\hline Quintile 2 & $0.57(0.25-1.30)$ & 0.18 & $0.75(0.31-1.79)$ & 0.51 \\
\hline Quintile 3 & $0.32(0.13-0.75)$ & 0.01 & $0.42(0.17-1.02)$ & 0.05 \\
\hline Quintile 4 & $0.28(0.11-0.73)$ & 0.01 & $0.33(0.12-0.91)$ & 0.03 \\
\hline Quintile 5 (most marginalized) & $0.12(0.04-0.35)$ & $<.01$ & $0.13(0.04-0.41)$ & $<0.01$ \\
\hline \multicolumn{5}{|l|}{ Health care service region (LHIN) } \\
\hline Toronto Central (7) & Reference & - & Reference & - \\
\hline Erie St. Clair (1) & $2.08(0.49-8.88)$ & 0.32 & $2.91(0.61-13.82)$ & 0.18 \\
\hline South West (2) & $2.19(0.63-7.62)$ & 0.22 & $2.97(0.81-10.80)$ & 0.10 \\
\hline Waterloo Wellington (3) & $1.56(0.34-7.17)$ & 0.57 & $1.90(0.39-9.22)$ & 0.43 \\
\hline Hamilton Niagara Haldimand Brant (4) & $0.44(0.12-1.66)$ & 0.22 & $0.35(0.08-1.48)$ & 0.15 \\
\hline Central West (5) & $0.26(0.03-2.15)$ & 0.21 & $0.25(0.03-2.38)$ & 0.23 \\
\hline Mississauga Halton (6) & $0.43(0.11-1.73)$ & 0.23 & $0.55(0.13-2.31)$ & 0.41 \\
\hline Central (8) & $0.46(0.11-1.82)$ & 0.27 & $0.62(0.13-2.90)$ & 0.54 \\
\hline Central East (9) & $0.71(0.19-2.71)$ & 0.62 & $0.88(0.21-3.60)$ & 0.86 \\
\hline South East (10) & $0.69(0.10-4.84)$ & 0.70 & $0.80(0.10-6.49)$ & 0.84 \\
\hline Champlain (11) & $0.67(0.18-2.48)$ & 0.55 & $0.63(0.16-2.44)$ & 0.50 \\
\hline North Simcoe Muskoka (12) & $0.59(0.10-3.62)$ & 0.57 & $0.47(0.07-3.31)$ & 0.45 \\
\hline North East (13) & $0.86(0.13-5.71)$ & 0.87 & $0.94(0.13-6.73)$ & 0.95 \\
\hline North West (14) & $0.59(0.03-11.12)$ & 0.73 & $0.57(0.01-25.16)$ & 0.77 \\
\hline \multicolumn{5}{|l|}{ Grouped Regions $^{\mathrm{d}}$} \\
\hline Southern Ontario (all southern LHINs) & Reference & - & Reference & - \\
\hline $\begin{array}{l}\text { Northern Ontario (North East \& North } \\
\text { West) }\end{array}$ & $0.94(0.25-3.54)$ & 0.93 & $1.04(0.26-4.21)$ & 0.95 \\
\hline
\end{tabular}


Table 4: (Continued)

\begin{tabular}{|c|c|c|c|c|}
\hline & $\operatorname{AOR}(95 \% \mathrm{CI})^{\mathrm{ab}}$ & $P$ value & $\operatorname{AOR}(95 \% \mathrm{CI})^{\mathrm{ac}}$ & P value \\
\hline \multicolumn{5}{|c|}{ Health care utilization in previous 2 years } \\
\hline \multicolumn{5}{|c|}{ All health care visits } \\
\hline $30+$ visits & Reference & - & Reference & - \\
\hline$<30$ visits & $0.22(0.10-0.45)$ & $<0.01$ & $0.22(0.10-0.46)$ & $<0.01$ \\
\hline \multicolumn{5}{|c|}{ Emergency department visits } \\
\hline Any visit & Reference & - & Reference & - \\
\hline No visit & $0.99(0.55-1.80)$ & 0.98 & $1.00(0.54-1.85)$ & 0.99 \\
\hline \multicolumn{5}{|c|}{ Psychiatrist visits } \\
\hline Any visit & Reference & - & Reference & - \\
\hline No visit & $0.08(0.04-0.16)$ & $<0.01$ & $0.07(0.04-0.16)$ & $<0.01$ \\
\hline \multicolumn{5}{|c|}{ Geriatrician visits } \\
\hline Any visit & Reference & - & Reference & - \\
\hline No visit & $1.73(0.61-4.87)$ & 0.30 & $2.27(0.77-6.69)$ & 0.14 \\
\hline \multicolumn{5}{|c|}{ Neurologist visits } \\
\hline $4+$ visits & Reference & - & Reference & - \\
\hline $1-3$ visits & $0.23(0.11-0.47)$ & $<0.01$ & $0.27(0.13-0.57)$ & $<0.01$ \\
\hline No visit & $0.01(0.00-0.07)$ & $<0.01$ & $0.02(0.00-0.13)$ & $<0.01$ \\
\hline \multicolumn{5}{|c|}{ Rostered to a primary care physician } \\
\hline Yes & Reference & - & Reference & - \\
\hline No & $1.27(0.53-3.01)$ & 0.59 & $1.19(0.49-2.88)$ & 0.70 \\
\hline \multicolumn{5}{|c|}{$\begin{array}{l}\text { PD medication classes utilized in previous } 2 \\
\text { years }\end{array}$} \\
\hline $0-2$ & Reference & - & Reference & - \\
\hline $3-4$ & - & - & $1.86(1.00-3.58)$ & 0.05 \\
\hline $5+$ & - & - & $4.77(2.01-11.33)$ & $<0.01$ \\
\hline
\end{tabular}

$\mathrm{AOR}=$ adjusted odds ratio; $\mathrm{CI}=$ confidence interval; LHIN $=$ Local Health Integration Network; ON-Marg = Ontario Marginalization Index; $\mathrm{PD}=$ Parkinson's disease

${ }^{\mathrm{a}} 747$ patients included in subgroup (155 DBS cases and 592 controls), with 693 patients included in analyses (153 DBS cases and 540 controls).

${ }^{\mathrm{b}}$ Adjusted for all domains of the ON-Marg (residential instability, material deprivation, dependency, and ethnic concentration); overall illness (ADGs); diagnoses of dementia and psychosis; number of prior psychiatrist, geriatrician, and neurologist visits; and family physician status.

${ }^{\mathrm{c}}$ Adjusted for all domains of the ON-Marg (residential instability, material deprivation, dependency, and ethnic concentration); overall illness (ADGs); diagnoses of dementia and psychosis; number of prior psychiatrist, geriatrician, and neurologist visits; family physician status; and use of any levodopa, non-ergot dopamine agonist, ergot dopamine agonist, MAO-B inhibitor, COMT inhibitor, anticholinergic for PD, and amantadine.

'Ontario's three DBS surgery sites are all located in Southern Ontario.

$(0-2)$ in the previous 2 years, those who used a greater number of PD medications (5+ classes) were more likely to undergo DBS surgery.

Within Canada, knowledge of DBS efficacy for the treatment of PD, dystonia, and disabling tremor is increasing. ${ }^{20}$ In spite of knowledge growth, the utilization of DBS appears to be nonuniform from a geographical perspective. Recently, a national study examined differences in the use of DBS surgery for any indication by provincial or territorial location, rural or non-rural location, and socioeconomic status. ${ }^{20}$ During the two-year study period (2015-2016), investigators found that 347 (48\%) of the 722 DBS surgeries performed in Canada were completed in Ontario, which coincided with the national DBS surgery rate (10 per million population per year). Conversely, relative to the national DBS surgery rate, the DBS surgery rate was significantly higher in Saskatchewan (374\%) and significantly lower in both Quebec (40\%) and Newfoundland and Labrador (32\%). Investigators found no differences in the use of DBS surgery within provinces by rural/non-rural residence or socioeconomic status. ${ }^{20}$ Reported findings are important in advancing our understanding of the drivers of potential disparities in DBS use; however, should be interpreted with caution since they are not disorder specific and the definition of rurality (town with $<1000$ people) employed by authors did not account for access to local specialty care or the distance patients had to travel to receive surgery.

We found geographic differences in the use of DBS surgery for PD in Ontario, which is consistent with known provincial variations in less commonly performed procedures such as iridectomy, colposcopy, and gastrectomy. ${ }^{21,22}$ Variations in the 
use of surgical procedures may reflect uncertainty about appropriate use. ${ }^{21}$ In Ontario, we believe that the observed differences in DBS surgery for PD by LHIN are most likely attributed to differences in care process as opposed to access barriers or patient distance from the closest movement disorder clinic. One such care process to consider is patient referral between primary care providers, movement disorder specialists, and neurosurgeons, or lack thereof. Within the Erie St. Clair and South West LHINs, specialist referral pathways and community-based PD support groups in proximity to London Health Sciences Centre, one of Ontario's three DBS surgery sites [London Health Sciences Centre, South West LHIN (2); Toronto's University Health Network, Toronto Central LHIN (7); The Ottawa Hospital, Champlain LHIN (11)], have been established. The increased use of DBS surgery for PD in these areas may reflect care processes that facilitate referrals for DBS. Similarly, the increased use of DBS surgery by northern Ontario residents, living hundreds of miles from the closest movement disorder clinic or DBS surgery site, could be driven by established referral networks of locums and visiting neurologists, and the availability of provincially funded northern health travel grants for specialty care. This potential explanation is supported by findings from an Ontario study of barriers to accessing specialty care in rural communities, which revealed that patients do not perceive travelling long distances as a major barrier to their care. ${ }^{23}$ Regional differences in DBS surgery were not observed in our subgroup analyses of patients $67+$ years of age or after accounting for PD medication use within the subgroup. These findings may be attributed to differences in patterns of health care utilization among older adults with PD compared to other PD populations. Further studies comparing health care utilization patterns between younger and older PD populations may therefore help to explain our subgroup findings.

Prior Canadian investigations have shown that ethnic minorities have lower rates of health care utilization and are therefore less likely to be "high-cost users" than Caucasians, ${ }^{24}$ particularly for mental health services. ${ }^{25,26}$ Our finding that patients living in visible minority concentrated neighborhoods have lower odds of DBS surgery compared to those residing in predominantly Caucasian neighborhoods coincides with reported race/ethnic differences in DBS utilization for PD in the US. ${ }^{8,27}$ Although lower use of DBS by those living in Ontario's most ethnically concentrated neighborhoods is not linked to lack of health insurance, it may in-part be explained by several factors. Biological differences in the progression of PD, burden of PD compared to comorbid diseases that are more malignant among ethnic minorities, language barriers, and differences in health-seeking behavior or patient preferences could partially explain our observations. Self-reported data show that Canadian visible minorities are less likely to have been admitted to hospital [odds ratio $(\mathrm{OR})=0.83,95 \% \mathrm{CI}=0.70-0.98]$, tested for prostate-specific antigen $(\mathrm{OR}=0.64,95 \% \mathrm{CI}=0.52-0.79)$, administered a mammogram $(\mathrm{OR}=0.68,95 \% \mathrm{CI}=0.59-0.80)$, or given a Pap test $(\mathrm{OR}=0.47,95 \% \mathrm{CI}=0.39-0.56)$ than Caucasian populations. ${ }^{28}$ If care-seeking behavior and/or patient preference contribute to decreased use of DBS surgery for PD among visible minorities, it is possible that by the time patients seek specialty care or pharmacological interventions have been exhausted, DBS neurosurgery contraindications have developed (such as diagnoses of dementia, stroke, or cancer). ${ }^{29}$ Lastly, as seen with patient perception of risk in joint replacement surgery, ${ }^{30}$ it may also be possible that minority populations perceive greater risk with DBS surgery than Caucasians. Future studies are needed to understand the nature of ethnic differences in DBS surgery for PD.

Regular neurologist care in PD has previously been shown to be associated with improved health outcomes, including lower odds of hospitalization and readmission for several PD-related illnesses and increased survival. ${ }^{11,31}$ Our findings that more frequent health care visits and neurologist follow-up are associated with undergoing DBS surgery suggest that routine specialty care for PD may play an important role in increasing access to DBS. Furthermore, our finding that patients receiving DBS surgery were more likely than PD controls to be treated with a greater number of distinct PD medication classes in the previous two years suggests that DBS is infrequently used as an early PD intervention in Ontario. This is likely to change in coming years since recent literature shows that compared to best medical therapy, use of DBS for PD is beneficial in earlier disease stages prior to exhausting multi-drug treatment regimens, especially in improving rest tremor and quality of life. ${ }^{32-35}$ While the risks and benefits of DBS for PD should be carefully weighed for each patient, further analysis of administrative claim and pharmacy data may provide insight into the number of PD patients in Ontario who may be eligible for DBS surgery.

There are numerous strengths to our study. Our cohort included all residents eligible to receive publicly funded medical services. As such, our results present a population-level picture of DBS use for PD within a universal health care setting. We employed a modified version of a validated algorithm for parkinsonism [sensitivity $=72.3 \%$; specificity $=99.9 \%$; positive predictive value $(\mathrm{PPV})=79.5 \%$; negative predictive value (NPV) $=99.9 \%]^{16}$ to identify eligible patients with PD in our study. Most reference standard parkinsonism cases included in the development of the original parkinsonism algorithm had PD (83\%), which supports our use of the adapted algorithm to identify patients with PD. Modifications to the algorithm were the exclusion of parkinsonism conditions not attributed to PD and were therefore presumed to increase PPV and otherwise minimally affect algorithm performance. Additionally, subgroup analyses restricted to older populations allowed us to examine the effects of PD medication use on receipt of DBS surgery. For these reasons, our findings regarding factors associated with DBS surgery for PD may be generalizable to other regions with universal insurance for health services, including other Canadian provinces or territories and European countries.

Our study is not without limitations. Since we retrospectively analyzed health administrative datasets, it is possible that exposures and outcomes were misclassified in some instances. However, misclassification of studied exposures and DBS surgery is presumed to be infrequent and to minimally bias modeled associations, likely toward the null. ${ }^{36}$ Populations with publicly funded insurance other than the Ontario Health Insurance Plan, such as First Nations people living on reserves and serving members of the Canadian Forces, were not included in our analyses. Our findings may therefore be less applicable to their PD care. Although we leveraged design and analytical approaches to minimize bias, we were unable to measure and control for PD severity and health care-seeking behavior, and may not be aware of all established networks that may facilitate referral for DBS surgery. The possibility of residual confounding exists. For 
example, PD severity may confound regional differences reported within our study, especially since there are very few neurologists with expertise in movement disorders practicing in northern Ontario. Compared to southern populations with PD, it is possible that by the time patients residing in northern Ontario are referred to a movement disorder specialist, their PD is more advanced and they are more likely deemed eligible for DBS surgery. Our analyses of northern regions and subgroups included small sample sizes; observed associations should therefore be interpreted with caution. Lastly, due to the exploratory nature of our study, we did not correct for multiple comparisons. We would therefore suggest that similar studies be performed in other populations with universal health care coverage to determine replicability. Despite these limitations, our study adds to the limited data on factors associated with DBS surgery for PD among populations with universal health care coverage.

\section{Conclusions and Future Directions}

In conclusion, our analyses reveal variations in the use of DBS for PD in Ontario. Specifically, we identified regional and neighborhood-level differences in the use of DBS. Findings from our study also highlight potential benefits of regular neurologist care and suggest that patterns of PD medication use may serve to identify candidates for DBS surgery. Effectively caring for PD is a multidisciplinary team effort, often involving input from patients, their family and care partners, family physicians, neurologists and other specialists, and pharmacists. It is recommended that specialty care referrals be made soon after the diagnosis of PD in order to maximize quality of life benefits that may be achieved through advanced therapeutic interventions, which may include DBS surgery. Where appropriate, the risks and benefits of DBS should be thoroughly discussed.

Study replication is warranted in other regions with universal health insurance; however, our results suggest that observed variations in DBS use may reflect differences in specialist referral pathways, patient health care-seeking behavior or preference, or biological need for DBS. Future quantitative and qualitative studies should seek to confirm and explain the reported variations within our study, as they may point to underutilization that is preventable.

\section{Acknowledgements}

Parts of this material are based on data and/or information compiled and provided by CIHI. However, the analyses, conclusions, opinions, and statements expressed in the material are those of the author(s) and not necessarily those of CIHI. We thank IMS Brogan Inc. for use of their Drug Information Database. We also thank Immigration, Refugees and Citizenship Canada for use of their Ontario immigration application record data.

\section{FUNDING}

This study was supported by the ICES Western site. ICES is funded by an annual grant from the Ontario Ministry of Health and Long-Term Care (MOHLTC). Core funding for ICES Western is provided by the Academic Medical Organization of Southwestern Ontario (AMOSO), the Schulich School of Medicine and Dentistry (SSMD), Western University, and the Lawson Health Research Institute (LHRI). The opinions, results, and conclusions reported in this paper are those of the authors and are independent from the funding sources. No endorsement by ICES, AMOSO, SSMD, LHRI, or the Ontario MOHLTC is intended or should be inferred. This study was also supported by the Northern Ontario Academic Medicine Association (NOAMA) Clinical Innovation Opportunities Fund Award, Project No: C-17-20.

\section{Disclosures}

The authors declared no potential conflicts of interest with respect to the research, authorship, and/or publication of this article. DS reports other financial activities from Hoffman - La Roche, outside the submitted work.

\section{Statement of Authorship}

All authors provided study design input. BL performed all data analyses and provided guidance on statistical analyses. ML, LR, JAGC, AWW, and DS led the interpretation of results. JAGC drafted the final manuscript. All authors contributed to manuscript revisions and approve the final manuscript.

\section{SUPPLEMENTARY MATERIAL}

To view supplementary material for this article, please visit https://doi.org/10.1017/cjn.2020.79.

\section{REFERENCES}

1. Parkinson Canada. A plan for Parkinson's in Ontario. Available at: http://www.parkinson.ca/wp-content/uploads/OntAdvocacy_ 8.5x11_F.pdf; accessed September 30, 2019.

2. Anderson D, Beecher G, Ba F. Deep brain stimulation in Parkinson's disease: new and emerging targets for refractory motor and nonmotor symptoms. Parkinsons Dis. 2017;2017:5124328.

3. Giugni JC, Okun MS. Treatment of advanced Parkinson's disease. Curr Opin Neurol. 2014;27(4):450-60.

4. Okun MS. Deep-brain stimulation for Parkinson's disease. N Engl J Med. 2012;367(16):1529-38.

5. Martinez-Ramirez D, Hu W, Bona AR, Okun MS, Wagle Shukla A. Update on deep brain stimulation in Parkinson's disease. Transl Neurodegener. 2015;4:12.

6. Ponce FA, Lozano AM. Deep brain stimulation state of the art and novel stimulation targets. Prog Brain Res. 2010;184:311-24.

7. Chan AK, McGovern RA, Brown LT, et al. Disparities in access to deep brain stimulation surgery for Parkinson disease: interaction between African American race and Medicaid use. JAMA Neurol. 2014;71(3):291-9.

8. Willis AW, Schootman M, Kung N, Wang XY, Perlmutter JS, Racette BA. Disparities in deep brain stimulation surgery among insured elders with Parkinson disease. Neurology. 2014;82(2): 163-71.

9. Dahodwala N, Xie M, Noll E, Siderowf A, Mandell DS. Treatment disparities in Parkinson's disease. Ann Neurol. 2009;66(2): $142-5$.

10. Safarpour D, Thibault DP, DeSanto CL, et al. Nursing home and end-of-life care in Parkinson disease. Neurology. 2015;85(5): 413-9.

11. Willis AW, Schootman M, Evanoff BA, Perlmutter JS, Racette BA. Neurologist care in Parkinson disease: a utilization, outcomes, and survival study. Neurology. 2011;77(9):851-7.

12. Government of Canada. Mapping connections: an understanding of neurological conditions in Canada. Available at: https://www. canada.ca/en/public-health/services/reports-publications/mappingconnections-understanding-neurological-conditions.html; accessed September 30, 2019

13. Harrington DW, Wilson K, Rosenberg M, Bell S. Access granted! barriers endure: determinants of difficulties accessing specialist 
care when required in Ontario, Canada. BMC Health Serv Res. 2013;13:146.

14. Dunlop S, Coyte PC, McIsaac W. Socio-economic status and the utilisation of physicians' services: results from the Canadian National Population Health Survey. Soc Sci Med. 2000;51(1):123-33.

15. Benchimol EI, Smeeth L, Guttmann A, et al. The REporting of studies Conducted using Observational Routinely-collected health Data (RECORD) statement. PLoS Med. 2015;12(10):e1001885.

16. Butt DA, Tu K, Young J, et al. A validation study of administrative data algorithms to identify patients with Parkinsonism with prevalence and incidence trends. Neuroepidemiology. 2014;43(1):28-37.

17. Matheson, FI; Ontario Agency for Health Protection and Promotion (Public Health Ontario). 2016 Ontario marginalization index: user guide. Toronto, ON: Providence St. Joseph's and St. Michael's Healthcare; 2018. Joint publication with Public Health Ontario.

18. MacLeod H. Local health integration networks: build on their purpose. Healthc Manageme. 2015;28(6):242-6.

19. Weiner JP, Abrams C. The Johns Hopkins ACG system: technical reference guide version 10.0. Available at: https://www. healthpartners.com/ucm/groups/public/@hp/@ public/documents/ documents/cntrb_035024.pdf; accessed September 30, 2019.

20. Honey CM, Malhotra AK, Tamber MS, Prud'homme M, Mendez I, Honey CR. Canadian Assessment of deep brain stimulation access: the Canada study. Can J Neurol Sci. 2018;45(5):553-8.

21. Feinberg AE, Porter J, Saskin R, Rangrej J, Urbach DR. Regional variation in the use of surgery in Ontario. CMAJ Open. 2015;3(3): E310-6.

22. Mahar AL, El-Sedfy A, Dixon M, et al. Geographic variation in surgical practice patterns and outcomes for resected nonmetastatic gastric cancer in Ontario. Current Oncol. 2018;25(5):e436-e43.

23. Sapru I, Cassidy K, Sibbald S. Perceived barriers to accessing specialized medical care in rural communities of Ontario: a pilot study. WURJ: Health and Natural Sciences. 2014;5(1 SE - Research Articles).

24. Rosella LC, Fitzpatrick T, Wodchis WP, Calzavara A, Manson H, Goel V. High-cost health care users in Ontario, Canada: demographic, socio-economic, and health status characteristics. BMC Health Serv Res. 2014;14:532.
25. Tiwari SK, Wang J. Ethnic differences in mental health service use among White, Chinese, South Asian and South East Asian populations living in Canada. Soc Psychiatry Psychiatr Epidemiol. 2008;43(11):866-71.

26. Chiu M, Amartey A, Wang X, Kurdyak P. Ethnic differences in mental health status and service utilization: a population-based study in Ontario, Canada. Can J Psychiatry. 2018;63(7):481-91.

27. Tafreshi AR, Landau MJ, Mack WJ, Cen SY, Amar AP. Commentary: trends in the use of deep brain stimulation for Parkinson disease. Neurosurgery. 2018;83(6):E244-e56.

28. Quan H, Fong A, De Coster C, et al. Variation in health services utilization among ethnic populations. CMAJ. 2006;174(6): 787-91.

29. deSouza RM, Moro E, Lang AE, Schapira AH. Timing of deep brain stimulation in Parkinson disease: a need for reappraisal? Ann Neurol. 2013;73(5):565-75.

30. Gandhi R, Razak F, Davey JR, Mahomed NN. Ethnicity and patient's perception of risk in joint replacement surgery. $\mathrm{J}$ Rheumatol. 2008;35(8):1664-7

31. Willis AW, Schootman M, Tran R, et al. Neurologist-associated reduction in PD-related hospitalizations and health care expenditures. Neurology. 2012;79(17):1774-80.

32. Weaver FM, Follett K, Stern M, et al. Bilateral deep brain stimulation vs best medical therapy for patients with advanced Parkinson disease: a randomized controlled trial. JAMA. 2009;301(1):63-73.

33. Hacker ML, DeLong MR, Turchan M, et al. Effects of deep brain stimulation on rest tremor progression in early stage Parkinson disease. Neurology. 2018;91(5):e463-e71.

34. Faraji AH, Richardson RM. Deep brain stimulation in early Parkinson's disease may slow rest tremor progression. Neurosurgery. 2019;84(1):E13-e4

35. Deuschl G, Schade-Brittinger C, Krack P, et al. A randomized trial of deep-brain stimulation for Parkinson's disease. N Engl J Med. 2006;355(9):896-908.

36. Wacholder S, Hartge P, Lubin JH, Dosemeci M. Non-differential misclassification and bias towards the null: a clarification. Occup Environ Med. 1995;52(8):557-8. 